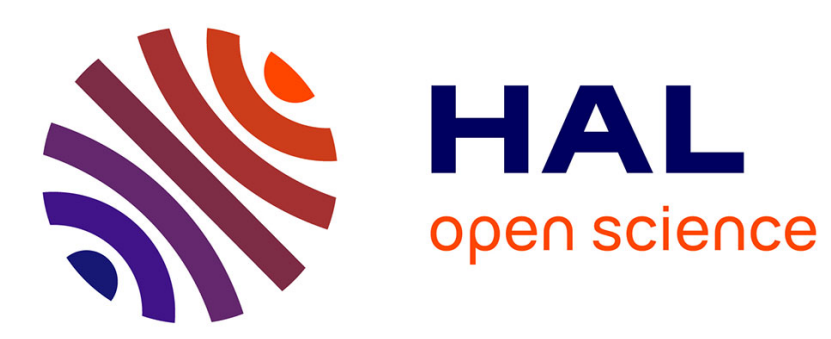

\title{
A Biaxial Fatigue Specimen for Uniaxial Loading
}

\author{
Daniel Bellett, Franck Morel, Anne Morel, Jean-Lou Lebrun
}

\section{To cite this version:}

Daniel Bellett, Franck Morel, Anne Morel, Jean-Lou Lebrun. A Biaxial Fatigue Specimen for Uniaxial Loading. Strain, 2011, 47 (3), pp.227-240. 10.1111/j.1475-1305.2009.00674.x . hal-00953546

\section{HAL Id: hal-00953546 https://hal.science/hal-00953546}

Submitted on 14 Mar 2014

HAL is a multi-disciplinary open access archive for the deposit and dissemination of scientific research documents, whether they are published or not. The documents may come from teaching and research institutions in France or abroad, or from public or private research centers.
L'archive ouverte pluridisciplinaire HAL, est destinée au dépôt et à la diffusion de documents scientifiques de niveau recherche, publiés ou non, émanant des établissements d'enseignement et de recherche français ou étrangers, des laboratoires publics ou privés. 


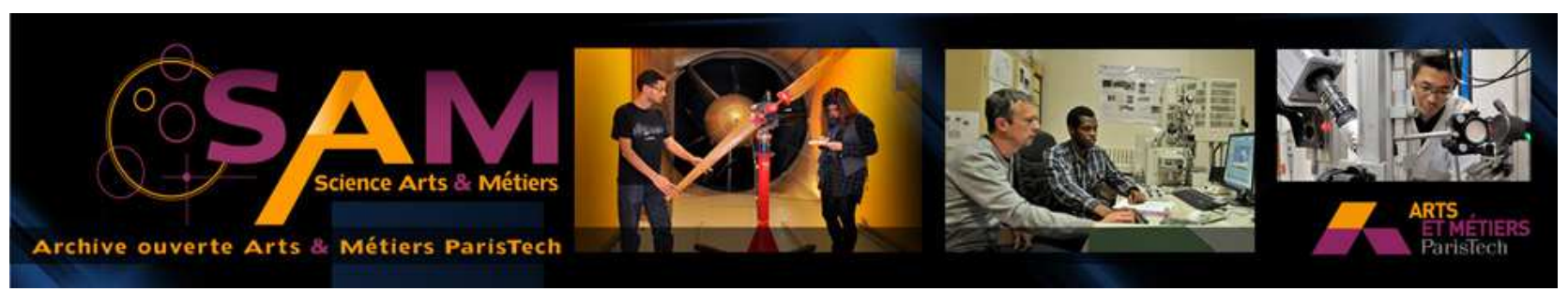

Science Arts \& Métiers (SAM)

is an open access repository that collects the work of Arts et Métiers ParisTech researchers and makes it freely available over the web where possible.

This is an author-deposited version published in: http://sam.ensam.eu Handle ID: .http://hdl.handle.net/10985/7805

\section{To cite this version :}

Daniel BELLETT, Franck MOREL, Anne MOREL, Jean-Lou LEBRUN - A Biaxial Fatigue Specimen for Uniaxial Loading - Strain - Vol. 47, n³, p.227-240 - 2011 


\title{
A Biaxial Fatigue Specimen for Uniaxial Loading
}

\author{
D. Bellett, F. Morel, A. Morel and J.-L. Lebrun \\ Arts et Métiers ParisTech, CER Angers, Laboratoire Procédés Matériaux Instrumentation (LMPI), 2 Bd du Ronceray, BP 93525,49035 \\ Angers Cedex I, France
}

\begin{abstract}
The aim of this paper is to present a novel un-notched fatigue test specimen in which a biaxial stress state is achieved using a uniaxial loading condition. This allows the problem of multiaxial fatigue to be studied using relatively common one-axis servo-hydraulic testing machines. In addition the specimen presented here is very compact and can be made using a small volume of material $(100 \times 40 \times 4.5 \mathrm{~mm})$. For this specimen, the degree of biaxiality, defined by the parameter $\boldsymbol{k}=\sigma_{22} / \sigma_{11}$ is equal to approximately 0.45 . The specimen geometry was optimised using the Dang Van multi-axial fatigue criterion. In addition to use as a fatigue specimen, it has been demonstrated that the biaxial specimen presented here is also suitable for biaxial tensile tests, to determine the rupture strength of a material in a biaxial stress state. Two different materials have been investigated: The first was wrought aluminium 2024-O in the form of $5 \mathrm{~mm}$ sheets. The second was a cast aluminium-silicon alloy AlSi7Cu0.5Mg0.3, commonly used in automotive and aeronautical applications. The fatigue strengths were determined at $2 \times 10^{6}$ cycles and at various R-ratios using a staircase procedure. For the aluminium 2024, it is shown that the biaxial stress state increases the maximum permissible first principal stress when compared to the uniaxial condition. However, in terms of the cast aluminium alloy, it has been demonstrated that this type of fatigue specimen is not suitable for materials containing casting defects, in particular microshrinkage pores, because the volume of material, in which the stress state is biaxial, is not large enough.
\end{abstract}

KEY WORDS: AL 2024-O, AlSi7Cu0.5Mg0.3, biaxial, fatigue, specimen

\section{Introduction}

Fatigue crack initiation and growth is one of the principal reasons for the failure of mechanical components subject to fluctuating loads and despite the enormous volume of research done over a period of more than 100 years, our understanding of the phenomena is still not complete. This is mostly due to the complexity of the fatigue problem and is also due to the practical obstacles involved in generating reliable fatigue data, under complex loading conditions.

The simplest loading condition that can be reproduced in the laboratory results in a uniaxial stress state, where only one component of the stress tensor is present. This is the case in uniaxial tensile fatigue tests and four-point rotating or alternating bending fatigue tests. There exists in the open literature a large volume of data for the plain specimen fatigue strength of most engineering materials loaded in these ways. Furthermore, one axis fatigue testing machines used for these tests types are relatively common.
The situation becomes considerably more complicated if we wish to test a material in a biaxial cyclic stress state. The biaxial problem most often studied is constant frequency combined tension/torsion, either in-phase or out-of-phase. The resulting cyclic stress state, defined in terms of the global Cartesian coordinate system, is given in Equation 1. For this loading condition there is a relatively large body of fatigue data available in the open literature, although considerably less than for the uniaxial case.

$$
\begin{aligned}
& {\left[\begin{array}{cc}
\sigma_{x x}(t) & \tau_{x y}(t) \\
\tau_{x y}(t) & 0
\end{array}\right]} \\
& =\left[\begin{array}{cc}
\sigma_{x x \_ \text {mean }} & \tau_{x y \_ \text {mean }} \\
\tau_{x y \_ \text {mean }} & 0
\end{array}\right] \\
& \quad+\left[\begin{array}{cc}
\sigma_{x x \_ \text {amp }} \sin (\omega t) & \tau_{x y \_a m p} \sin \left(\omega t+\varphi_{x y}\right) \\
\tau_{x y \_ \text {amp }} \sin \left(\omega t+\varphi_{x y}\right) & 0
\end{array}\right]
\end{aligned}
$$

Similarly, it is possible to generate a cyclic biaxial stress field with two normal components of the stress 
tensor as described by Equation 2. This stress state forms the object of this work.

$$
\begin{aligned}
& {\left[\begin{array}{cc}
\sigma_{x x}(t) & 0 \\
0 & \sigma_{y y}(t)
\end{array}\right]} \\
& =\left[\begin{array}{cc}
\sigma_{x x \_ \text {mean }} & 0 \\
0 & \sigma_{y y \_ \text {mean }}
\end{array}\right] \\
& \quad+\left[\begin{array}{cc}
\sigma_{x x \_ \text {amp }} \sin (\omega t) & 0 \\
0 & \sigma_{y y \_a m p} \sin \left(\omega t+\varphi_{y y}\right)
\end{array}\right]
\end{aligned}
$$

In the following a brief review of the different biaxial fatigue specimens and apparatus commonly used to generate this cyclic biaxial stress state is presented.

\section{Review of biaxial fatigue specimens and apparatus}

Figures 1-4 show different specimen geometries and loading conditions that have been used to study fatigue under a cyclic biaxial stress field with two normal components of the stress tensor. The first

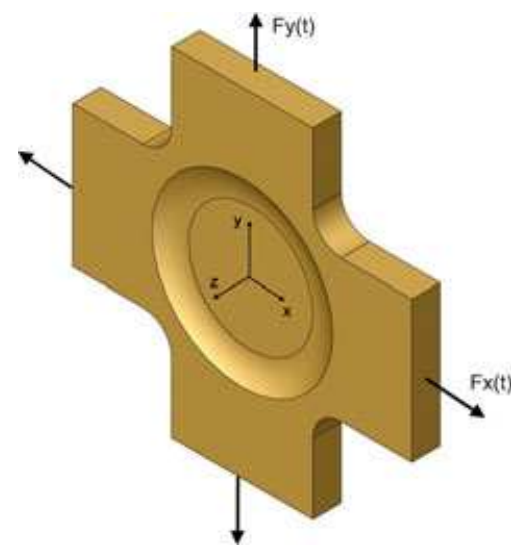

Figure I: Cruciform type biaxial fatigue specimen

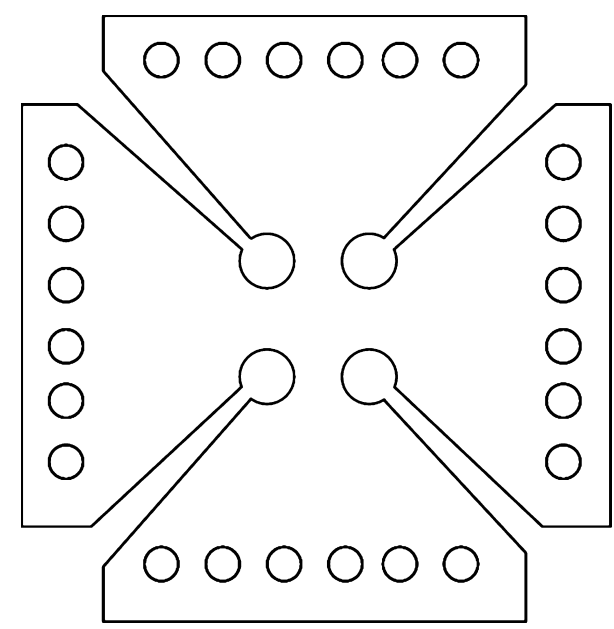

Figure 2: A typical cruciform fatigue specimen [5]

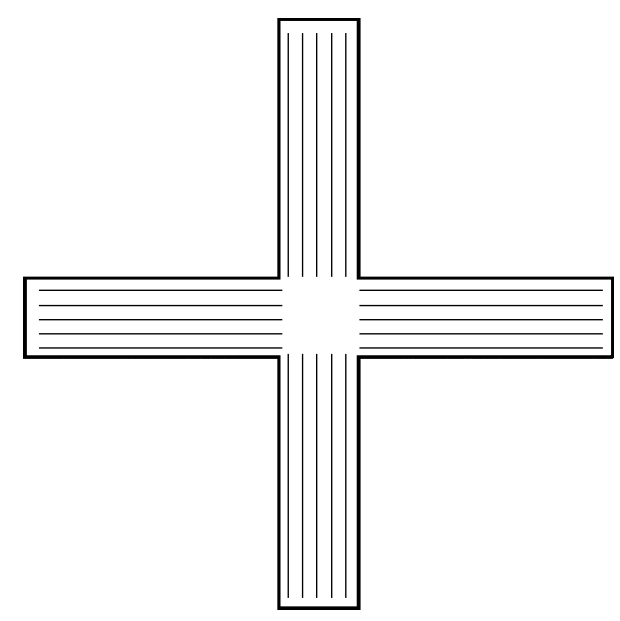

Figure 3: A cruciform fatigue specimen with slots in the load applying arms to ensure a homogenous stress state [5]

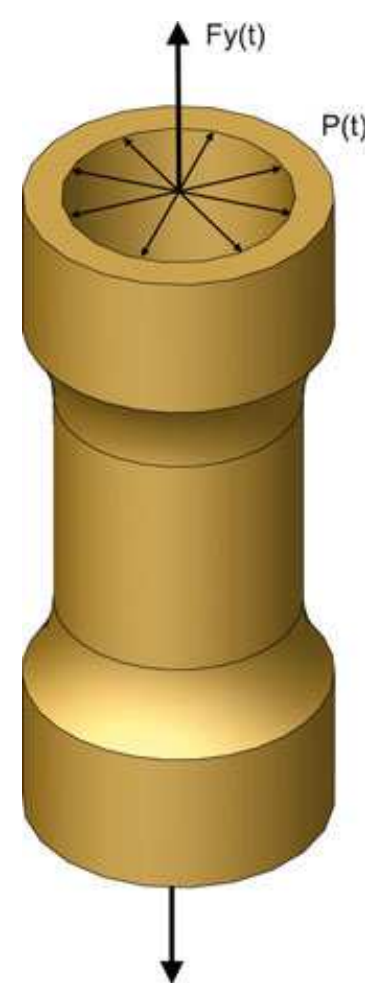

Figure 4: Tensile/Internal pressure biaxial fatigue specimen

three are cruciform type specimen and the last is a tensile/internal pressure specimen.

The problems encountered with these specimen types is that, firstly they are time consuming to manufacture but more importantly the tests require highly specific and expensive multi-axis fatigue testing machines. Consequently there exists very little fatigue data with this type of loading for only a small number of materials. Much of this fatigue data was generated 20 to 30 years ago in Germany [1-4].

As already stated, the purpose of this paper is to present a novel biaxial fatigue specimen in which the stress state in the crack initiation zone is characterised 


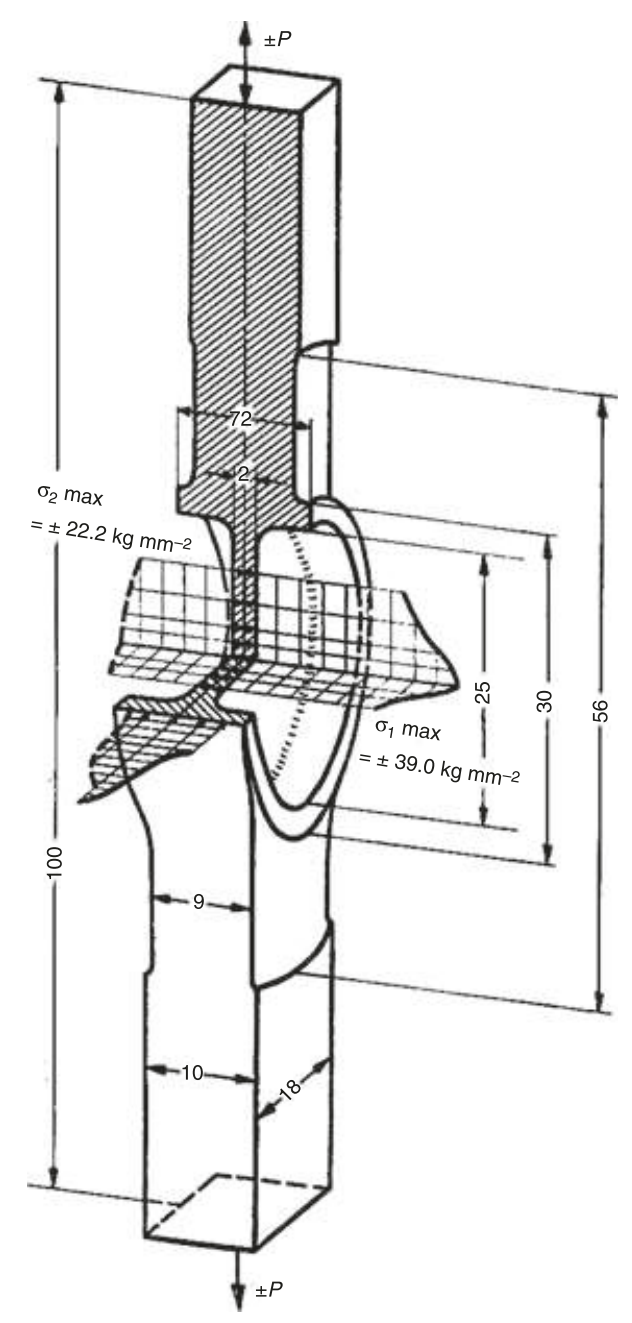

Figure 5: A biaxial specimen [6] for uniaxial loading presented the 1943

by two cyclic normal stress components, while loading the specimen uniaxially. However, there have been other attempts made to implement the same idea. Figure 5 shows a biaxial fatigue specimen for uniaxial loading, presented by Sawert [6] in 1943. Figures 6 and 7 show two biaxial testing apparatus that can be used to test cruciform specimens in a uniaxial testing machine $[7,8]$. Unfortunately, both of these concepts require a larger quantity of material to make the specimens, than was available in the present work.

\section{The Dang Van multiaxial fatigue criterion}

The Dang Van multiaxial fatigue criterion [9-11] is briefly discussed below because it is used in the following to optimise the shape of the biaxial specimen presented here. This criterion is valid for the high cycle fatigue regime and is a multi-scale approach based on the concept of elastic shakedown. That is, the fatigue process is considered on both the usual macroscopic scale, (in which the material is consid-

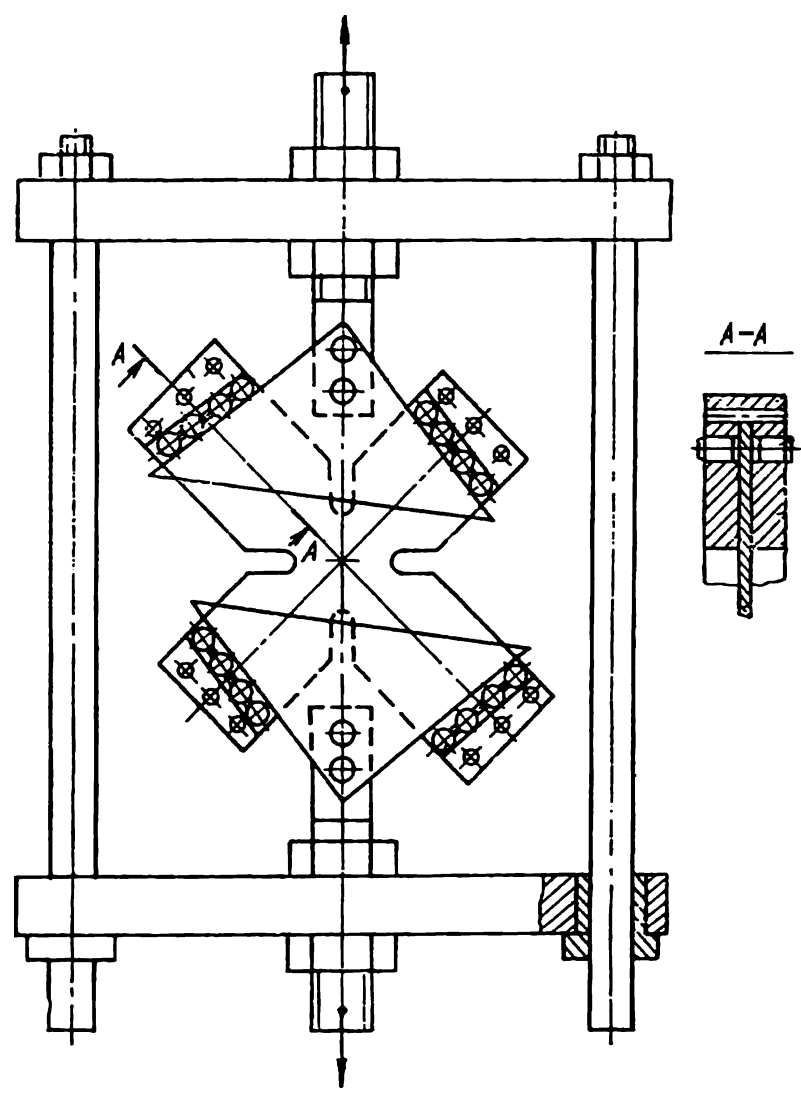

Figure 6: Biaxial testing apparatus for uniaxial loading [7]

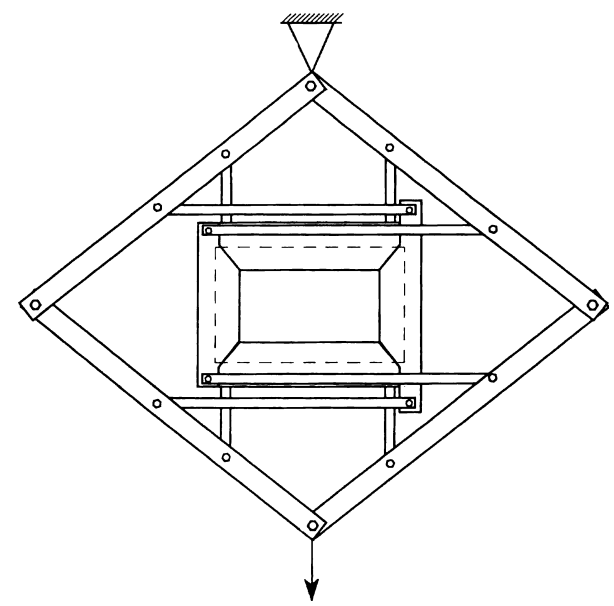

Figure 7: Biaxial testing apparatus for uniaxial loading [8]

ered to be homogeneous, as per the typical assumption in continuum solid mechanics) and on the mesoscopic scale or the scale of individual grains of the material. The Lin-Taylor hypothesis [12] is used in order to facilitate the passage from mesoscopic quantities (stress and strain) to macroscopic ones. The criteria can be summarised by the following statement: 'Microscopic fatigue crack initiation does not occur if the material is shaken-down elastically at both the macroscopic and mesoscopic scales, (or if 

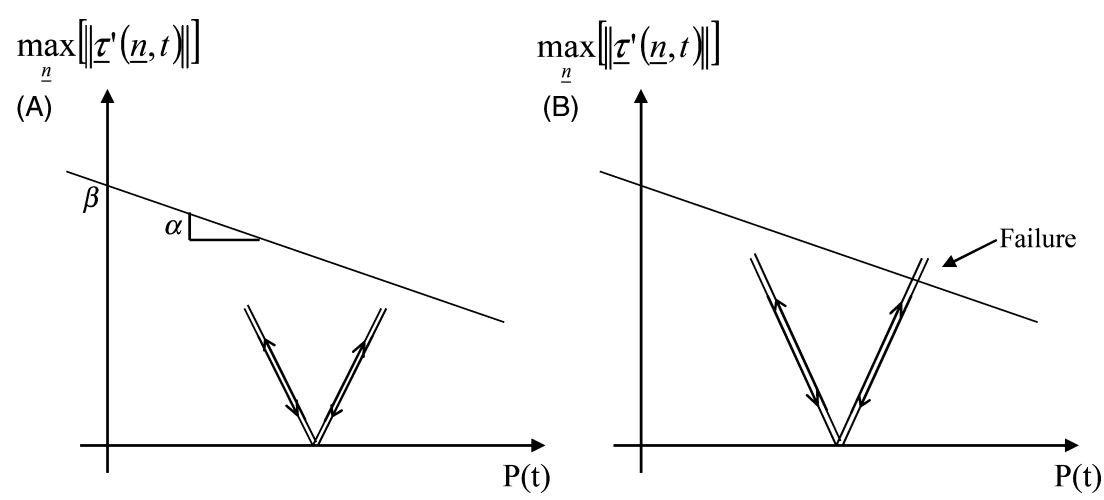

Figure 8: The Dang Van criterion (A) showing a load cycle in which failure is not predicted (B) in which failure is predicted

the material adapts elastically at all scales)'. Mathematically the criterion is represented by Equation 6 below and is shown schematically in Figure 8:

$\max _{t}\left\{\max _{\underline{n}}\left[\left\|\underline{\tau}^{\prime}(\underline{n}, t)\right\|+\alpha P(t)\right]\right\} \leq \beta$

where $P(t)$ is the hydrostatic stress as a function of time:

$P(t)=\frac{1}{3} \underline{\sigma}_{i i}(t)=\frac{1}{3} \underline{\underline{E}}_{i i}(t)$

and $\underline{\tau}^{\prime}(\underline{n}, t)$ is the mesoscopic shear stress on a plane defined by its normal vector, $\underline{n}$. The use of the criterion requires the double maximisation shown in Equation 3, in terms of the material plane $\underline{\mathrm{n}}$ and time, $t$. After the passage from the meso scale to the macro scale, the mesoscopic shear stress is shown to be equivalent to the amplitude of the macroscopic shear stress on the material plane, $T_{a}(\underline{n}, t)$. The concept of the minimum circumscribed circle [13] is used to define the amplitude of the macroscopic shear stress.

$\alpha$ and $\beta$ are two material parameters normally determined via the fatigue limits of the material in alternating tension-compression $\left(s_{-1}\right)$ and reversed torsion $\left(t_{-1}\right)$. In the plane of shear stress versus hydrostatic stress, the parameter $\alpha$ represents the slope of the line given by Equation 5 and $\beta$ is the y-intercept.

$\alpha=\frac{t_{-1}-\frac{s_{-1}}{2}}{\frac{s_{-1}}{3}} \quad \beta=t_{-1}$

\section{The New Biaxial Specimen}

The new specimen geometry is shown in Figure 9. It can be thought of as being similar to the cruciform shape shown in Figure 1. The two tear-shaped holes above and below the centreline of the specimen divide the 'lines of force' so that the centre point of the specimen experiences a biaxial stress state. In order that the fatigue crack initiates at the centre of the specimen the thickness in this region is reduced by machining semi-spherical depressions on both sides of the specimen.

Procedure for optimising the geometry of the specimen

In terms of the dimensions of the specimen the following constraints had to be met:

1 The cast aluminium material that was used (AlSi7Cu0.5Mg0.3) was machined from actual cast and heat-treated diesel engine cylinder heads and the maximum plate size that could be obtained was $100 \times 40 \times 4.7 \mathrm{~mm}$.

2 The wrought aluminium used (2024) was supplied in the form of $5 \mathrm{~mm}$ sheets.

3 A preliminary investigation showed that for a given geometrical configuration, decreasing the thickness at the centre of the specimen increases the likelihood of a fatigue crack initiating at the centre of the specimen, it also increases the degree
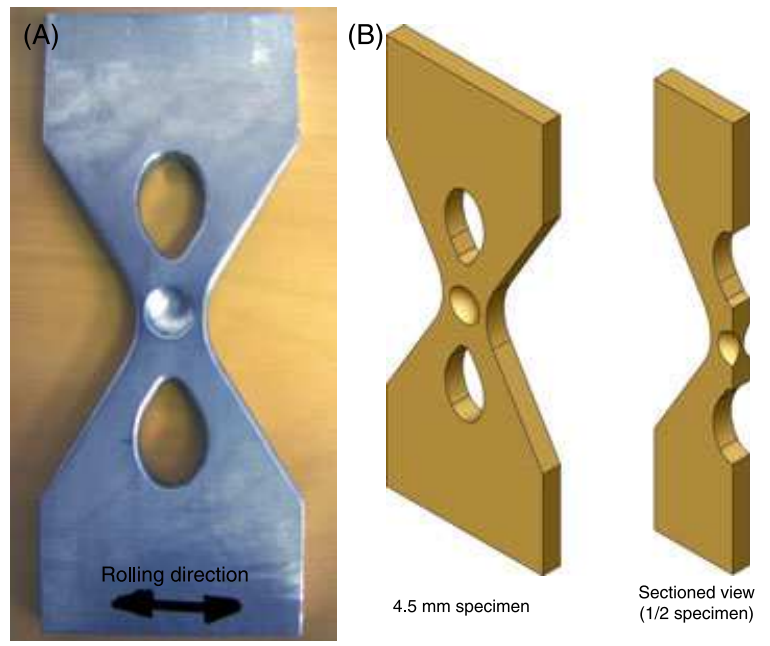

Figure 9: The new biaxial specimen 
of biaxiality. However, in order to ensure that the volume of material biaxially loaded is large enough to be representative of the macroscopic material behaviour, the smallest thickness at the centre of the specimen was limited to $1 \mathrm{~mm}$.

4 The specimen was manufactured using a numerically controlled milling machine and standard tool sizes. In particular, a standard $10 \mathrm{~mm}$ ball nose end milling tool was used to machine the semi-spherical depressions on both sides of the specimen.

The geometric form of the specimen was determined with two objectives in mind. The first was to ensure that fatigue initiation occurred at the centre of the specimen. In order to achieve this, the Dang Van multi-axial fatigue criterion was used. This criterion is discussed in section The Dang Van multiaxial fatigue criterion. The parameter $\mathrm{DV}_{\text {ratio }}$ was defined as per Equation 6 below. This parameter defines the relative likelihood of fatigue failure, according to the Dang Van criterion, between the centre point of the specimen and any other location on the specimen. A value of $\mathrm{DV}_{\text {ratio }}$ greater than 1.0 should ensure crack initiation occurs preferentially in the centre of the specimen.

$\max \left\{\right.$ DVratio $\left.=\frac{\left(T_{a}+\alpha P\right)_{\text {centre }}}{\left(T_{a}+\alpha P\right)_{\text {other }}}\right\}$

As the torsional fatigue limits of the materials investigated were not available, the parameter alpha was estimated to be 0.75 . This value was based on the authors experience using the Dang Van criterion for other aluminium alloys.

The second objective was to maximise the degree of biaxiality at the centre of the specimen, that is:

$\max \left\{k=\frac{\sigma_{2}}{\sigma_{1}}\right\}$

After a considerable number of finite element simulations using different geometries and dimensions, it was determined that the three geometric parameters having the greatest influence were $D, H$ and $R$ shown in Figure 10.

These three parameters were varied as follows:

- $D=[5.5$ to 9.5$] \mathrm{mm}$ in increments of $0.5 \mathrm{~mm}$.

- $H=[5.5$ to 9.5$] \mathrm{mm}$ in increments of $0.5 \mathrm{~mm}$.

- $R=[10,12,18] \mathrm{mm}$.

A macro in the APDL programming language of the ANSYS finite element program was used to create 243 different linear elastic models corresponding to each combination of $\mathrm{D}, \mathrm{H}$ and $\mathrm{R}$ above. The resulting response surfaces, for the two parameters $k$ and $\mathrm{DV}_{\text {ratio }}$ are presented in Figures 11 and 12.

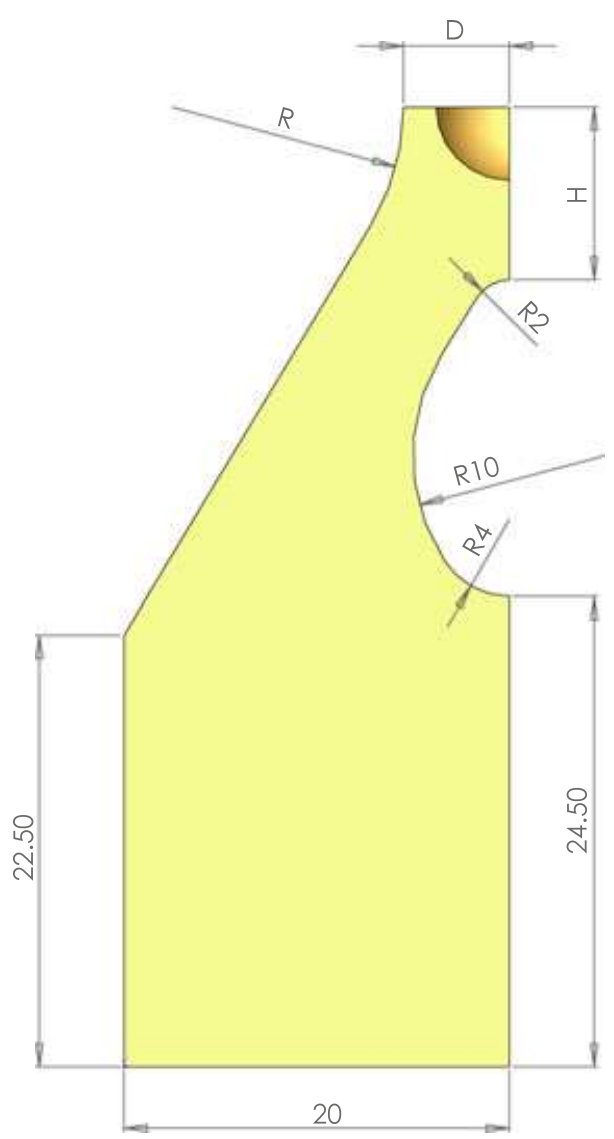

Figure 10: Specimen Geometry (1/4 model) showing the dimensions having the greatest influence $H, D$ and $R$

From the above it can be seen that, with this type of specimen it is possible to achieve a biaxiality ratio of very close to 1.0. Unfortunately, in this configuration, the Dang Van criterion predicts that the fatigue crack will not initiate in the centre of the specimen. Hence, a compromise between the two objective functions must be made. As the $\mathrm{DV}_{\text {ratio }}$ parameter is considered to be the most important, the following choice was made:

$$
D=5.5 \mathrm{~mm}, H=9.0 \mathrm{~mm} \text { and } R=12 \mathrm{~mm} \text {. }
$$

This corresponds to $k=0.45$ and $\mathrm{DV}_{\text {ratio }}=1.35$. In this geometrical configuration, the Dang Van criterion predicts that the probability of crack initiation is $35 \%$ higher at the centre of the specimen when compared to all other locations on the specimen. This was considered to be a large enough difference to take into account the uncertainties/errors in the Dang Van criterion. The final dimensions of the specimen are shown in Figure 13.

\section{Determination of the stress state}

Elastic-plastic finite element analyses of the biaxial specimens were done using the ANSYS FE code in order to determine the relationship between the 

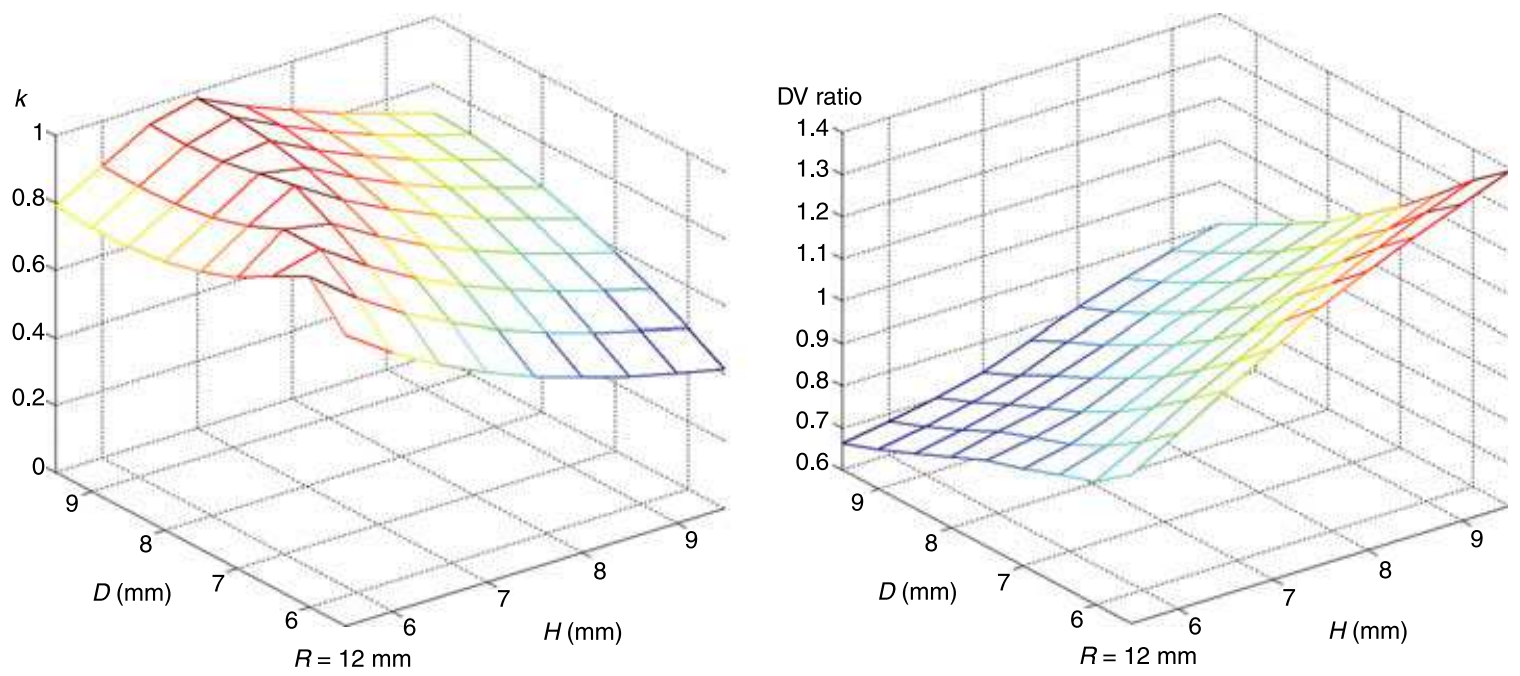

Figure I I: Response surfaces for $k$ and $\mathrm{DV}_{\text {ratio }}$ as a function of $\mathrm{D}$ and $\mathrm{H}$ (for $R=12 \mathrm{~mm}$ )
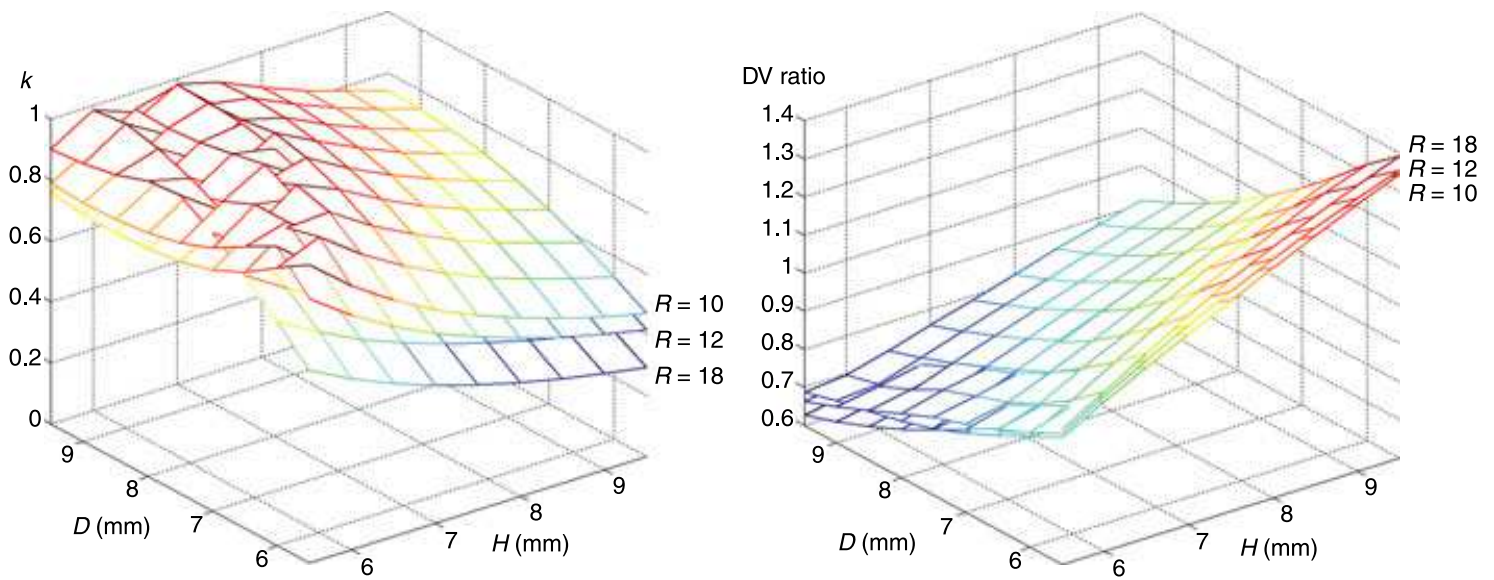

Figure 12: Response surfaces for $k$ and $\mathrm{DV}_{\text {ratio }}$ as a function of $\mathrm{D}, \mathrm{H}$ and $\mathrm{R}$

applied load and the stress state in the centre of the specimens. ANSYS Solid92 elements were used (i.e. 10-node tetrahedral elements) to generate a free mesh. The average element size in the biaxial zone of the specimen was $0.125 \mathrm{~mm}$ (i.e. eight elements through the $1 \mathrm{~mm}$ thickness at the centre of the specimen). For this mesh size, the FE stress results were shown to have converged to within an error of within $0.014 \%$. A separate FE model was built for each specimen to account for small variations in the dimension of the specimens, essentially due to the manual polishing procedure. These analyses used the measured monotonic stress-strain relationship, the von Mises yield criteria and isotropic hardening. Isotropic hardening was deemed appropriate because the material is assumed to be elastically shaken-down at the fatigue limit. Cyclic analyses using pure kinematic hardening showed that, at the experimentally determined fatigue limit, the reversed plastic strains in the centre of the specimen were insignificant (see Figure 14).
In order to confirm the FE results, a thermoelastic stress analysis was undertaken, using a commercially available infrared camera and dedicated thermoelastic stress analysis software. The specimen was cyclic loaded in the elastic range at a frequency of $10 \mathrm{~Hz}$. A thermal image of the specimen is shown in Figure 15. The stress distributions determined along the horizontal line in Figure 15 are plotted in Figure 16 for both the thermoelastic stress analysis and the FE analysis, for a charge of $2 \mathrm{kN}$. Note that these stress distributions represent the sum of the principal stress components. Figure 17 shows the decomposition of this sum into the principal stress components, as determined via the FE analysis.

It can be seen from Figure 16 that the stress distributions determined via the thermoelastic stress analysis and the FE analysis are in good agreement, with a maximum difference of approximately $10 \%$.

In addition, strain gauges were also used to calibrate the finite element analysis. Uniaxial gauges placed on an arm of the tear shaped hole (as shown in 

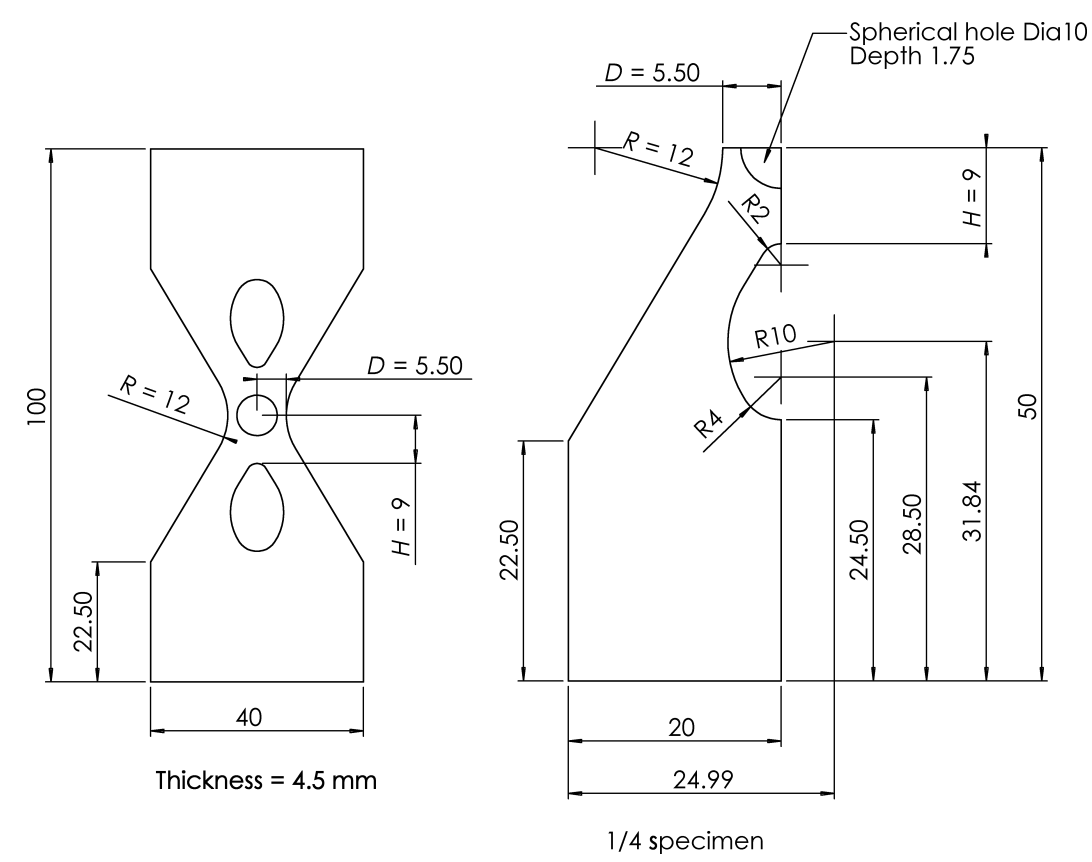

Figure 13: New biaxial specimen - final dimensions

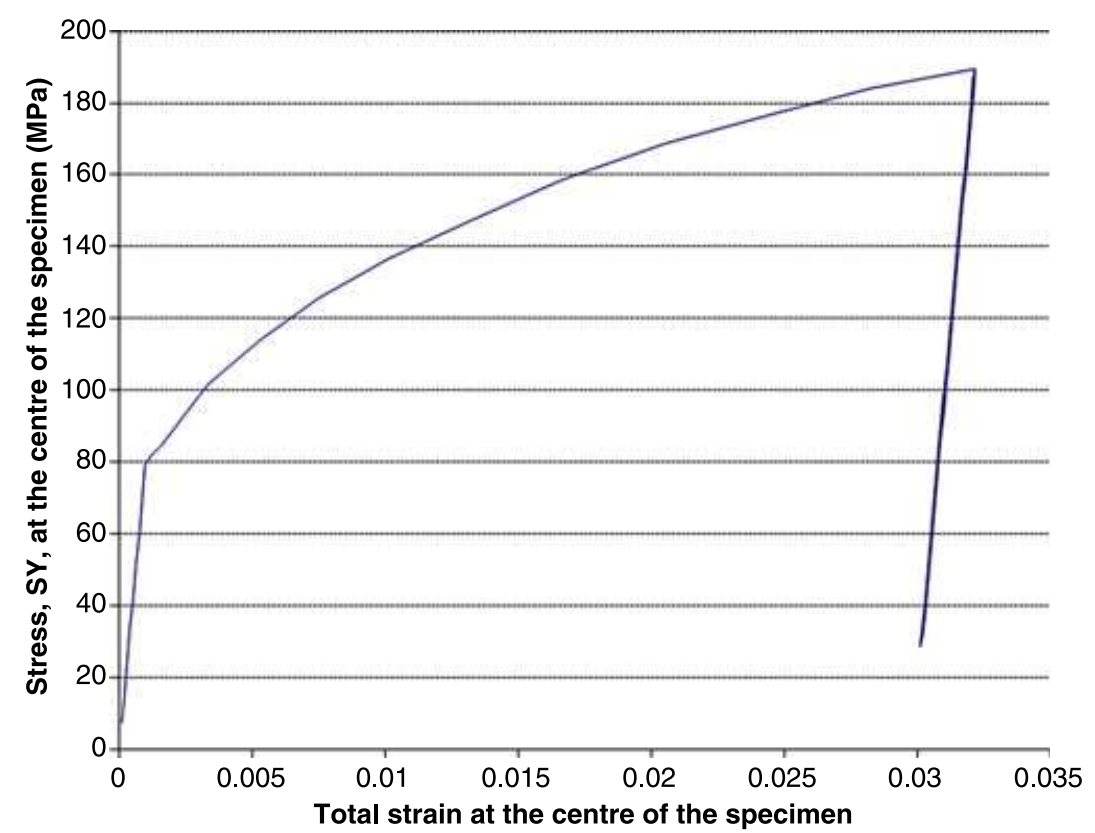

Figure 14: Calculated stress-strain relation of two complete loading cycles at the centre of the specimen, loaded at the fatigue limit, assuming pure kinematic hardening. This figure indicates that the material is elastically shaken-down at the fatigue limit

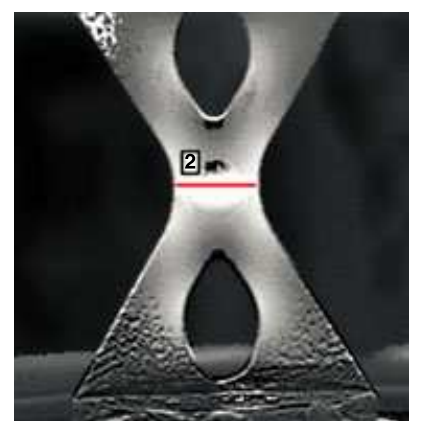

Figure 15: Thermal image of the biaxial specimen
Figure 18) were used on selected specimens. Again good agreement was found with the finite element analysis (see Table 1).

\section{Stress gradients}

It is well known that a stress gradient in the region of crack initiation can have a strong influence on fatigue behaviour. This can be highlighted by:

1 The difference in the plain specimen fatigue strengths determined in rotating bending and push-pull tests, and 


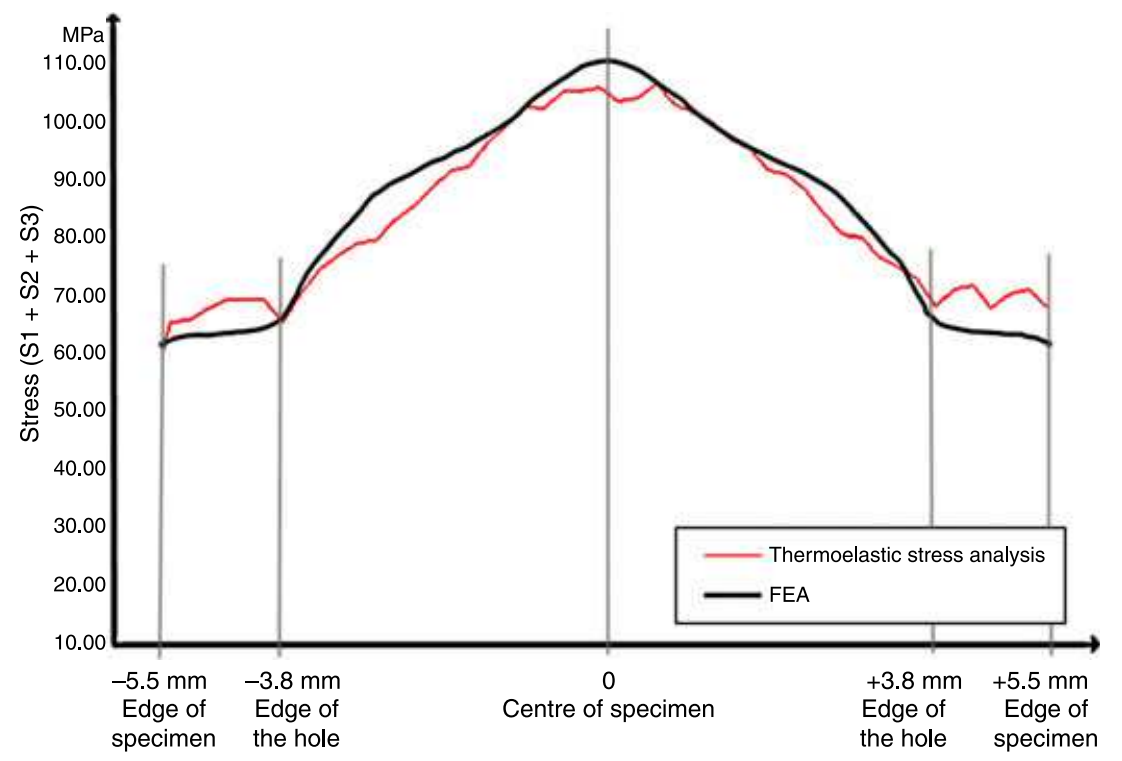

Figure 16: Comparison between the FE and thermoelastic stress analyses

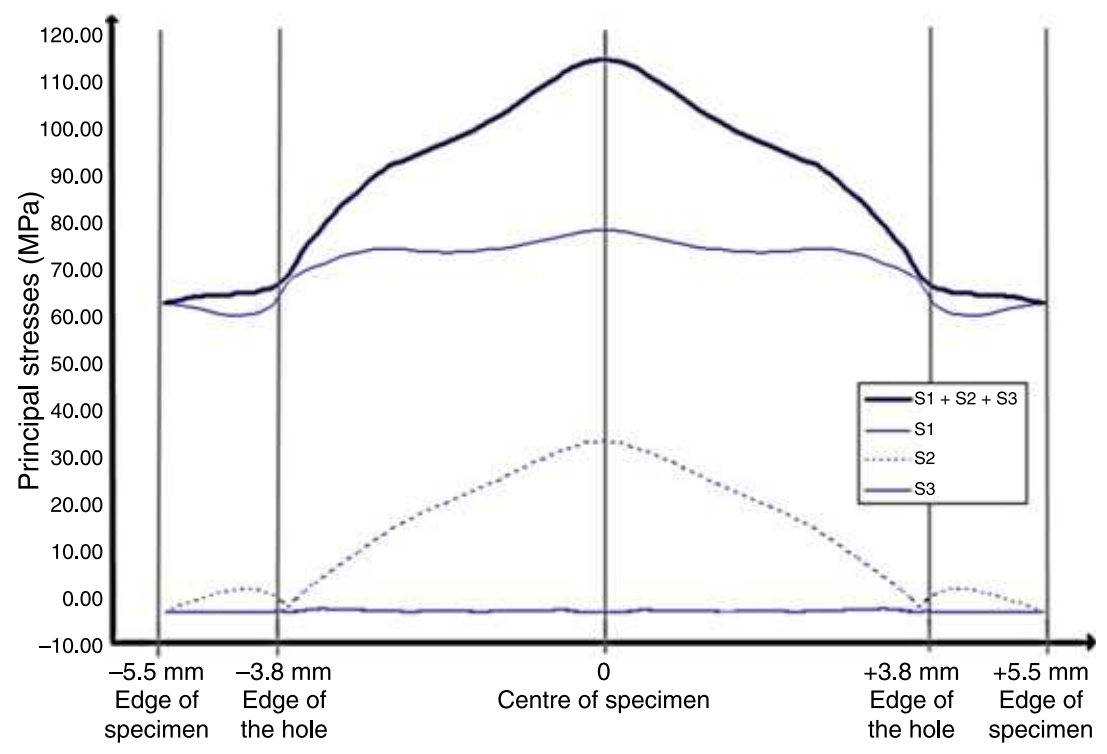

Figure 17: Finite element stress distribution calculated along the horizontal red line shown in Figure 15

2 By the so-called notch effect, although in the case of a notch, the stress gradient is not the only complicating factor.

Using the coordinate system shown in Figure 19A, B shows the evolutions of the normal stress in the $y$-direction (Sy) as a function of distance from the centre of the specimen, in negative $x, y$ and $z$ directions. Figure 19C shows the corresponding evolutions of the stress gradients. It can be seen that in each direction the stress gradients are not very high, with the largest value being $-2.5 \mathrm{MPa} / \mathrm{mm}$ in the through thickness or $z$-direction.

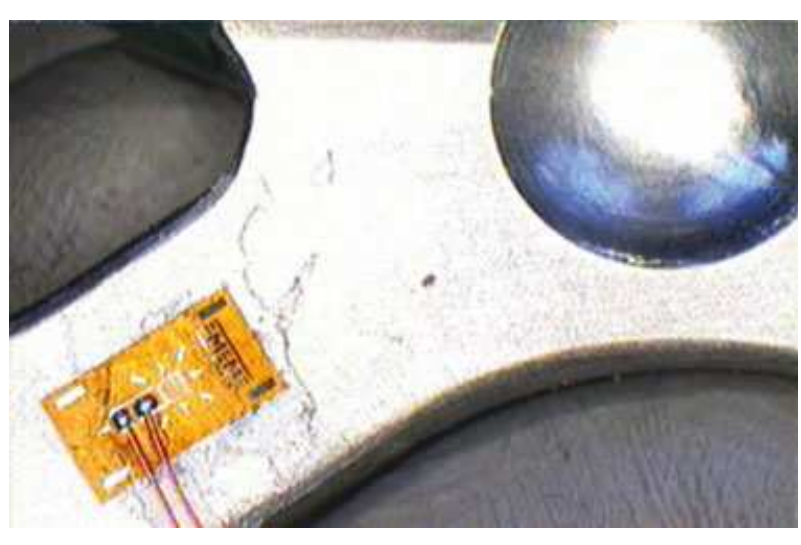

Figure 18: Position of strain gauges 
Table I: Comparison between strain gauge measurements and the calculated strain for the position shown in Figure 18

\begin{tabular}{lcc}
\hline Applied axial load $(\mathrm{kN})$ & Measured strain $(\mu \epsilon)$ & Calculated strain $(\mu \epsilon)$ \\
\hline 0 & 5 & 0.0 \\
1 & 232 & 226.1 \\
2 & 464 & 452.2 \\
3 & 696 & 678.3 \\
3.28 & 760 & 741.0 \\
\hline
\end{tabular}

\section{Another geometry - higher biaxiality}

In order to achieve a higher degree of biaxiality, while still predicting crack initiation at the centre of the specimen, a similar process to that outlined in section 2. The New Biaxial Specimen was undertaken using the same basic specimen geometry. The main change was that the thickness of the specimen was increased to $10 \mathrm{~mm}$. After the analysis the following dimensions were chosen.

$$
D=7 \mathrm{~mm}, H=8.0 \mathrm{~mm} \text { and } R=12 \mathrm{~mm} .
$$

This corresponds to $\mathrm{k}=0.625$ and $\mathrm{DV}_{\text {ratio }}=1.342$. Figure 20 shows the specimen. It should be noted that this specimen has not yet been tested.

\section{Experimental Results}

\section{Materials and experimental procedure}

Two materials were used in this work: (a) wrought aluminium 2024 and (b) cast aluminium A1Si7-

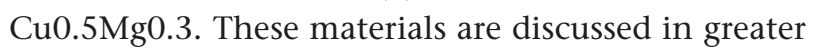
detail below.

\section{(A)}
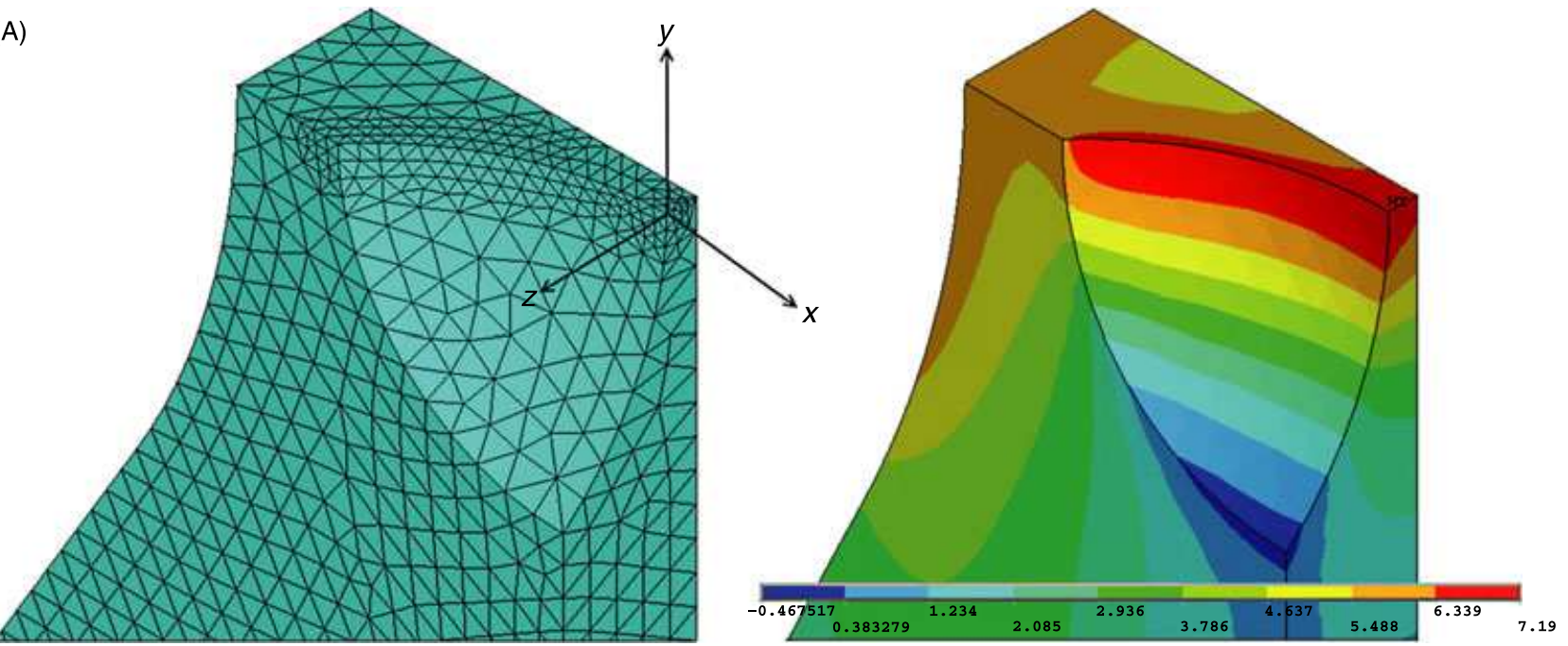

(B)
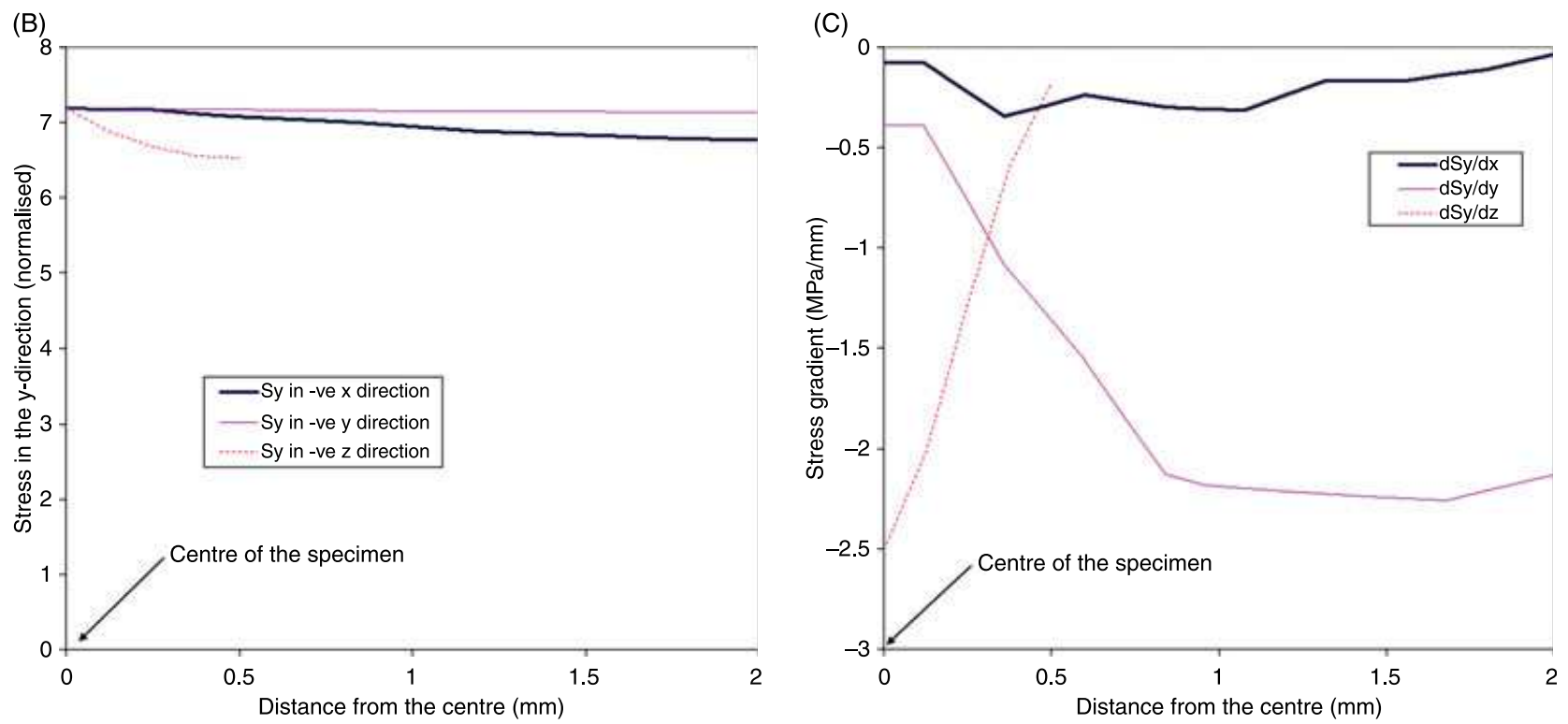

Figure 19: Stress gradients in the new biaxial specimen (A) FE mesh of $1 / 8$ model of the specimen (3 planes of symmetry) showing the coordinate system used below and the SY stress distribution for an applied pressure of $1 \mathrm{MPa}$ (B) Distributions of the normal stress Sy in the $x, y$ and $z$-directions (C) Stress gradients as a function of distance from the centre of the specimen 


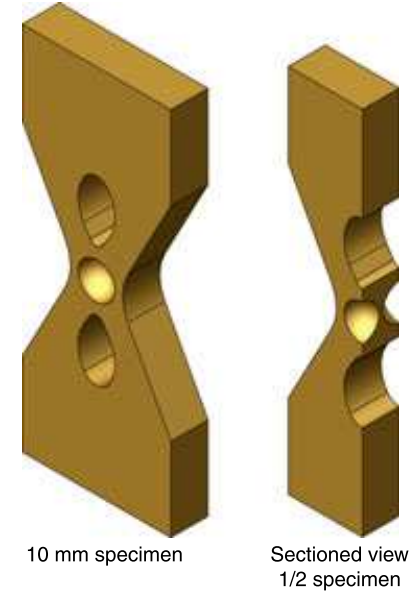

Figure 20: Thicker specimen designed to increase the biaxiality

\section{Wrought aluminium 2024-O}

This material was used in the annealed state and was supplied in sheets of $5 \mathrm{~mm}$ thickness. It consist of large elongated re-crystallised grains (aluminium rich solid solution), inside of which may be found large intermetallic precipitates, (principally $\mathrm{CuMgAl} 2$ ). Its mechanical properties are listed in Table 2. All fatigue specimens were taken so that the longitudinal axis of the specimen was perpendicular to the rolling direction.

\section{Cast aluminium AlSi7Cu0.5Mg0.3}

Fatigue specimens were made from material taken from cylinder heads manufactured for use in diesel automobile engines. The cylinder heads were gravity sand cast. During the casting process titanium and boron were added to the liquid metal in order to refine the size of the alpha-phase dendrites. Strontium was added to modify the shape of the silicon eutectic particles. The cast components were subsequently quenched and age hardened. The resulting mechanical properties of the material are listed in Table 3.

Figure 21 shows the material microstructure created as a result of the process described above. The material is composed of alpha-phase dendrites with an average Dendrite Arm Spacing (DAS) of approximately $90 \mu \mathrm{m}$. The eutectic silicon particles are greatly refined and spherical as the microstructure has been modified with strontium. The dark features

Table 2: Mechanical properties of aluminium 2024

\begin{tabular}{lll}
\hline $\begin{array}{l}0.2 \% \text { Yield } \\
\text { strength, } \\
\sigma_{Y}(\mathrm{MPa})\end{array}$ & $\begin{array}{l}\text { Ultimate } \\
\text { tensile strength, } \\
\sigma_{\text {UTS }}(\mathrm{MPa})\end{array}$ & $\begin{array}{l}\text { Percent } \\
\text { elongation at } \\
\text { break, A (\%) }\end{array}$ \\
\hline 82 & 189 & 23 \\
\hline
\end{tabular}

Table 3: Mechanical properties of Cast aluminium AlSi7-

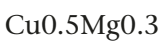

\begin{tabular}{lll}
\hline $\begin{array}{l}0.2 \% \text { yield } \\
\text { strength, }\end{array}$ & $\begin{array}{l}\text { Ultimate } \\
\text { tensile strength, } \\
\sigma_{Y}(\mathrm{MPa})\end{array}$ & $\begin{array}{l}\text { Percent } \\
\text { elongation at } \\
\text { break, A (\%) }\end{array}$ \\
\hline 251 & 288 & 2.1 \\
\hline
\end{tabular}

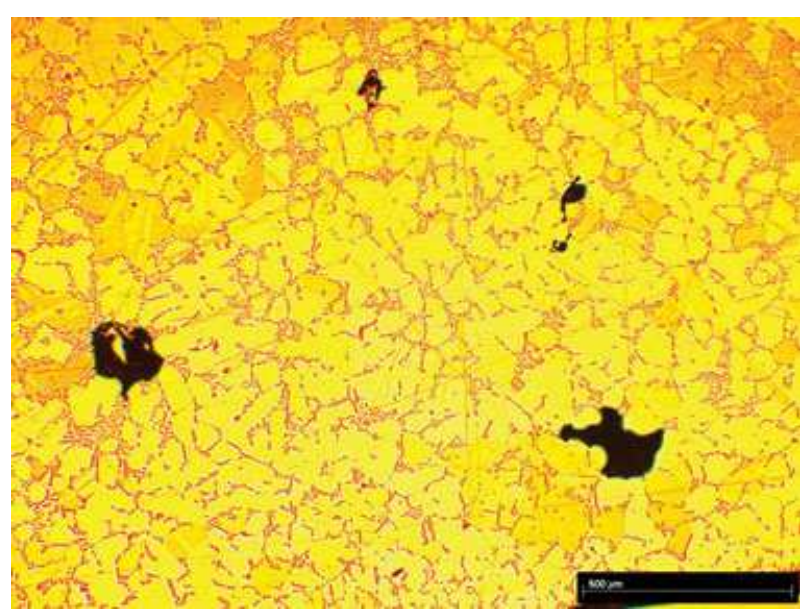

Figure 2 I: Microstructure of AlSi7Cu0.5Mg0.3

in Figure 21 are casting defects (micro-shrinkage pores) caused by the shrinkage of the liquid during solidification. In a complicated cast component like a cylinder head it is impossible to completely eliminate this type of defect. In the material discussed here the average defect size was $200 \mu \mathrm{m}$.

\section{Fatigue specimen preparation}

Uniaxial fatigue tests were undertaken using flat fatigue specimens with the geometry shown in Figure 22. Both uniaxial and biaxial specimens were manually polished using carbon-silicon sand paper to a roughness of approximately $\mathrm{Ra}=0.2 \mu \mathrm{m}$. The edges of the specimens were rounded, in an effort to reduce the experimental scatter due to edge effects.

\section{Fatigue tests results}

All fatigue tests were done using an Instron servohydraulic testing machine at room temperature and pressure, at a frequency of $30 \mathrm{~Hz}$.

\section{Al 2024 - uniaxial fatigue test results}

The staircase method was used to determine the plain specimen fatigue strengths of the 2024 material at $2 \times 10^{6}$ cycles at two different mean stresses (i.e. staircases in which the mean stress is held constant). The staircases are presented in Tables 4 and 5. The results are summarised in Table 6 and displayed on the constant life or Haigh diagram shown in Figure 23. 


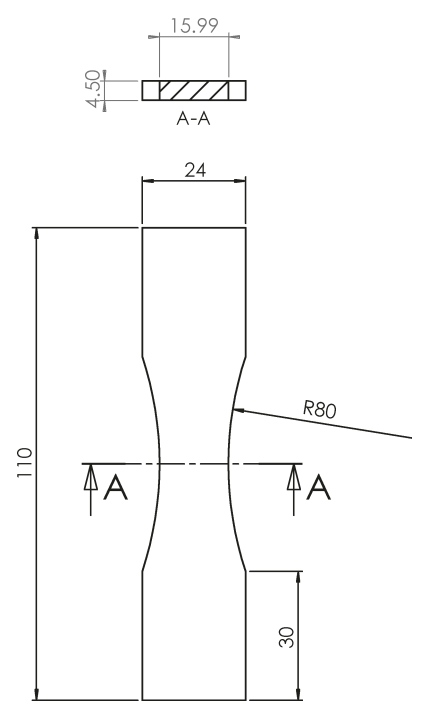

Figure 22: Uniaxial fatigue specimens

It can be seen from Figure 23 that this material conforms quite well to the prediction made by the Gerber parabola.

\section{Al 2024 - biaxial fatigue test results}

Figure 24 shows a typical fatigue failure of the biaxial specimen made from the aluminium 2024. It can be seen that the crack clearly initiates in the centre of the specimen in zone subjected to a biaxial stress state. This was found to be the case for $100 \%$ of the specimens tested.
Table 6: Summary of plain specimen, uniaxial fatigue strengths of Al 2024 at $2 \times 10^{6}$ cycles

\begin{tabular}{lcllrr}
\hline & $\begin{array}{l}\sigma_{\text {mean }} \\
(\mathrm{MPa})\end{array}$ & $\begin{array}{l}\sigma_{\mathrm{amp}} \\
(\mathrm{MPa})\end{array}$ & $\begin{array}{l}\sigma_{\max } \\
(\mathrm{MPa})\end{array}$ & $\begin{array}{l}\sigma_{\min } \\
(\mathrm{MPa})\end{array}$ & $R$ \\
\hline Uni. $R=-1$ & 0 & 87.5 & 87.5 & -87.5 & -1 \\
Uni. $R=0$ & 74.25 & 69.5 & 143.75 & 4.75 & 0.03 \\
\hline
\end{tabular}

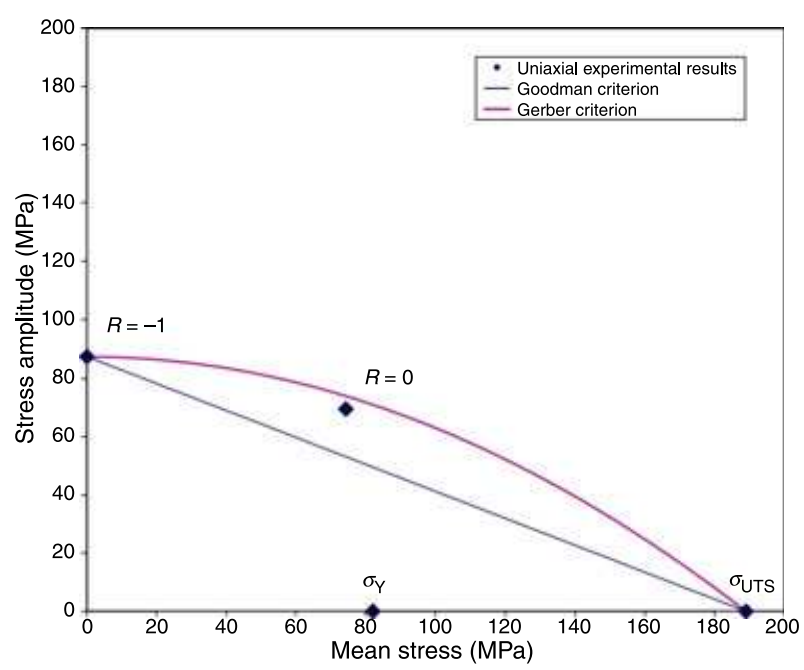

Figure 23: Uniaxial fatigue results for the $\mathrm{Al} 2024$ represented in the form of a Haigh Diagram

Table 4: Staircase (Al 2024, Uniaxial, $\sigma_{\text {mean }}=0 \mathrm{MPa}$ )

\begin{tabular}{|c|c|c|c|c|c|c|c|c|c|c|c|c|c|c|}
\hline No.: & & I & 2 & 3 & 4 & 5 & 6 & 7 & 8 & 9 & 1011 & & & \\
\hline Spec No. & & TI5 & $\mathrm{TI7}$ & TI8 & $\mathrm{T} 2 \mathrm{I}$ & $\mathrm{T} 23$ & $\mathrm{~T} 24$ & $\mathrm{~T} 26$ & T28 & T30 & & & & \\
\hline$\sigma_{\mathrm{a}}(\mathrm{MPa})$ & $R$ & & & & & & & & & & & i $N_{i}$ & $i N_{i}$ & $i^{2} N_{i}$ \\
\hline 95 & -1.00 & & $x$ & & & & & & & & & 30 & 0 & 0 \\
\hline 90 & -1.00 & 0 & & $x$ & & & & $x$ & & $x$ & & 21 & 2 & 4 \\
\hline 85 & -1.00 & & & & $x$ & & 0 & & 0 & & & 12 & 2 & 2 \\
\hline \multirow[t]{2}{*}{80} & -1.00 & & & & & 0 & & & & & & 01 & 0 & 0 \\
\hline & & & & & & & & & & & & $N=4$ & $A=4$ & $4 B=6$ \\
\hline $\mathrm{N}$ & & $2.0 \times 10^{6}$ & $1.78 \times 10^{5}$ & $5.31 \times 10^{5}$ & $5.25 \times 10^{5}$ & $2.0 \times 10^{6}$ & $2.0 \times 10^{6}$ & $7.92 \times 10^{5}$ & $2.0 \times 10^{6}$ & $5.95 \times 10^{5}$ & & & & \\
\hline
\end{tabular}

Table 5: Staircase (Al 2024, Uniaxial, $\sigma_{\text {mean }}=74.25 \mathrm{MPa}$ )

\begin{tabular}{|c|c|c|c|c|c|c|c|c|c|c|c|c|c|c|}
\hline No.: & & I & 2 & 3 & 4 & 5 & 6 & 7 & 8 & 9 & 1011 & & & \\
\hline Spec No.: & & T8 & T9 & TIO & TII & $\mathrm{T} 12$ & $\mathrm{~T} 13$ & $\mathrm{~T} 25$ & $\mathrm{~T} 27$ & T29 & & & & \\
\hline$\sigma_{\mathrm{a}}(\mathrm{MPa})$ & $R$ & & & & & & & & & & & $i N_{i}$ & $i N_{i}$ & $i^{2} N_{i}$ \\
\hline 75.75 & -0.010 & & & & $x$ & & $x$ & & & & & 30 & 0 & 0 \\
\hline 70.75 & 0.024 & & & 0 & & 0 & & $\times$ & & & & 22 & 4 & 8 \\
\hline 65.75 & 0.061 & & 0 & & & & & & $x$ & & & I I & I & I \\
\hline \multirow[t]{2}{*}{60.75} & 0.100 & 0 & & & & & & & & $x$ & & 01 & 0 & 0 \\
\hline & & & & & & & & & & & & $N=4$ & $A=5$ & $B=9$ \\
\hline N & & $2.0 \times 10^{6}$ & $2.0 \times 10^{6}$ & $2.0 \times 10^{6}$ & $1.35 \times 10^{6}$ & $2.0 \times 10^{6}$ & $4.47 \times 10^{5}$ & $4.91 \times 10^{5}$ & $9.78 \times 10^{5}$ & $1.24 \times 10^{6}$ & & & & \\
\hline
\end{tabular}




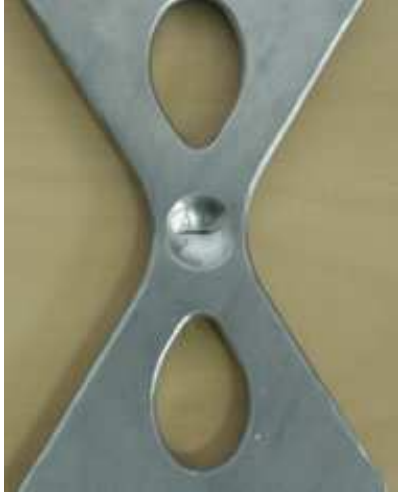

Figure 24: Typical fatigue failure of the biaxial specimen in $\mathrm{Al}$ 2024

As per the uniaxial tests, a staircase procedure was used to determine the average fatigue strength at $2 \times 10^{6}$ cycles. The staircase is presented in Table 7 , in terms of the first principal stress at the centre of the specimen. For this staircase, the mean first principal stress was held constant and equal to $105 \mathrm{MPa}$. The biaxial result is summarised in Table 8 .

\section{AlSi7Cu0.5Mg0.3 - Biaxial Fatigue Test Results}

The results of the biaxial fatigue specimens, tested using the cast aluminium material, were not at all successful. A total of 5 specimens were tested and in each case the fatigue crack initiated at a casting defect and not in the small biaxial zone situated in the centre of the specimen. Figure 25 show one such specimen where the crack initiated from the outside left edge of the specimen. In this position the stress state is effectively uniaxial.

\section{Discussion of fatigue results}

Figure 26 plots both the uniaxial and biaxial fatigue data for the wrought aluminium, on a Haigh diagram, in terms of the first principal stress. This diagram makes it clear that the biaxial stress state results in an increase in the maximum permissible first principal stress supported by the material.

Figure 27 shows an SEM image of a typical fatigue failure surface for the cast aluminium material AlSi7Cu0.5Mg0.3. A micro-shrinkage pore is appar-

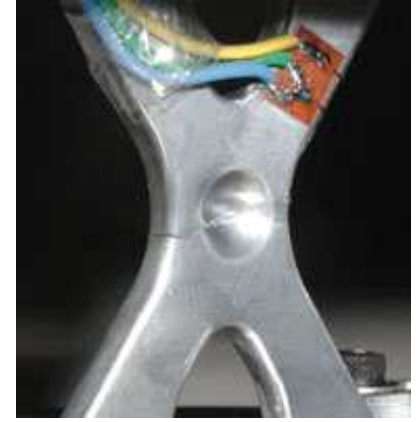

Figure 25: A biaxial fatigue specimen made from cast AlSi7Cu0.5Mg0.3 showing that crack initiation did not occur in the biaxial zone in the centre of the specimen

Table 8: Fatigue result (Al 2024, biaxial specimen)

\begin{tabular}{llll}
\hline & Mean stress & Stress amplitude & Load ratio \\
\hline $\begin{array}{l}\text { First principal } \\
\text { stress }\end{array}$ & $\sigma_{1, \text { mean }}=105 \mathrm{MPa}$ & $\sigma_{1, \text { amp }}=86 \mathrm{MPa}$ & $R=0.1$ \\
$\begin{array}{l}\text { Second principal } \\
\text { stress }\end{array}$ & $\sigma_{2, \text { mean }}=42 \mathrm{MPa}$ & $\sigma_{2, \text { amp }}=34.4 \mathrm{MPa}$ & \\
\hline
\end{tabular}

ent near the free surface of the specimen. This type of defect typically has a complex, very irregular form caused by the solidification of the $\alpha$-phase dendrites. From the figure it can be seen that crack initiation occurred from this defect. The effect of the foundry defects is to alter the fatigue initiation mechanism, so that in a uniform, macroscopic stress field, fatigue crack occur preferentially at the largest defects [14]. Hence, because the biaxial fatigue specimen present here, contains only a small volume of material solicited in uniform biaxial way, the probability of a crack initiating in this volume strongly depends on the probability of finding a large casting defect in the volume.

\section{Al 2024 - biaxial tensile tests}

The biaxial specimen (for uniaxial loading) has also been used in monotonic tensile tests to determine the rupture strength of the $\mathrm{Al} 2024$ material in a

Table 7: Staircase (Al 2024, Biaxial, $\left.\sigma_{1, \text { mean }}=105 \mathrm{MPa}\right)$

\begin{tabular}{|c|c|c|c|c|c|c|c|c|c|c|c|c|c|c|c|}
\hline No.: & & 1 & 2 & 3 & 4 & 5 & 6 & 7 & 8 & 9 & 1011 & & & & \\
\hline Spec No.: & & TB8 & TB7 & TB9 & TBII & $\mathrm{TB} / 3$ & $\mathrm{~TB} \mid 4$ & TBIO & TBI5 & TBI7 & & & & & \\
\hline$\sigma_{\mathrm{l}, \mathrm{amp}}$ & $R$ & & & & & & & & & & & i & $N_{i}$ & $i N_{i}$ & $i^{2} N_{i}$ \\
\hline 96 & 0.045 & & $\times$ & & $\times$ & & & & & & & & 2 & 4 & 8 \\
\hline 86 & 0.099 & 0 & & 0 & & $x$ & & $\times$ & & 0 & & & 2 & 2 & 2 \\
\hline \multirow[t]{2}{*}{76} & 0.160 & & & & & & 0 & & 0 & & & 0 & 0 & 0 & 0 \\
\hline & & & & & & & & & & & & & $N=4$ & $A=6$ & $B=10$ \\
\hline $\mathrm{N}$ & & $2.0 \times 10^{6}$ & $1.84 \times 10^{5}$ & $2.0 \times 10^{6}$ & $2.29 \times 10^{5}$ & $1.49 \times 10^{6}$ & $2.0 \times 10^{6}$ & $5.13 \times 10^{5}$ & $2.0 \times 10^{6}$ & $2.0 \times 10^{6}$ & & & & & \\
\hline
\end{tabular}




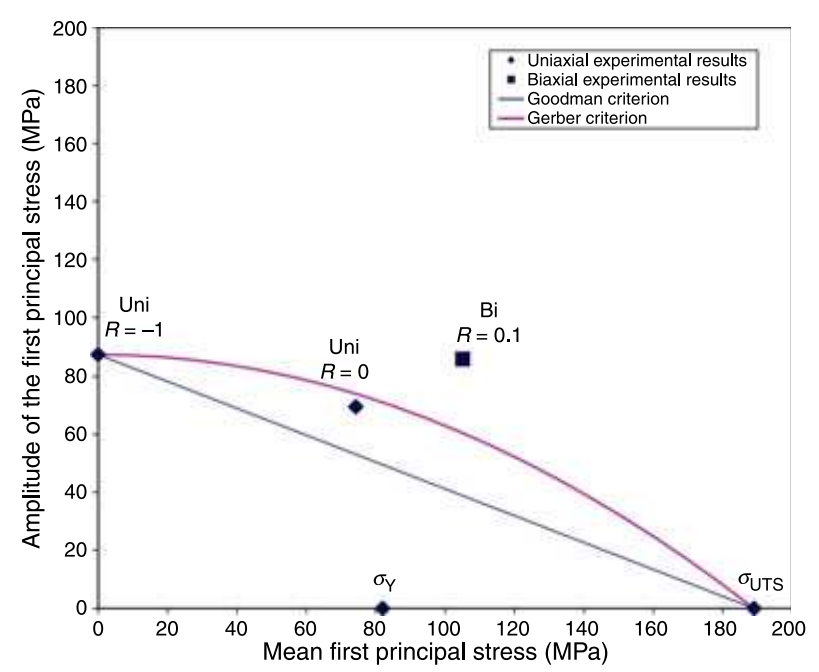

Figure 26: Hiagh diagram (in terms of the 1st principal stress) for $\mathrm{Al} 2024$

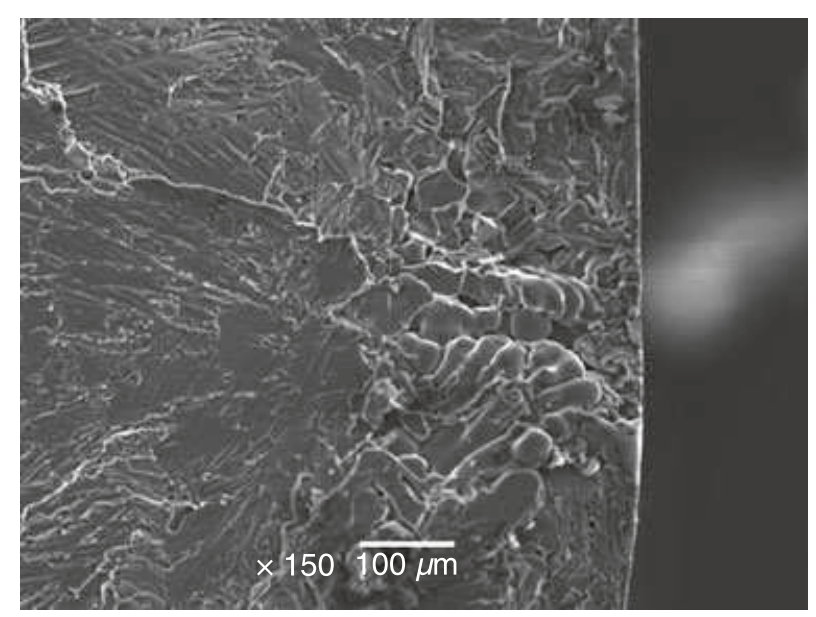

Figure 27: Typical fatigue rupture surface of AlSi7Cu0.5Mg0.3 showing crack initiation from a surface micro-shrinkage pore biaxial stress state. As it can be seen in Figure 28, a drop in the load is observed when the material ruptures in the biaxial zone, in the centre of the specimen.

\section{Conclusions}

A novel type of fatigue specimen has been presented, in which crack initiation occurs in a small, biaxially solicited zone, even when the specimen is loaded uniaxially. This specimen can be fabricated using a relatively small quantity of material (i.e. a plate of $100 \times 40 \times 4.5 \mathrm{~mm}$ ). The approach used to determine and optimise the shape of the specimen has been outlined.

Two different aluminium materials have been tested in fatigue using this specimen geometry. It has been demonstrated that:

- The stress gradients in the biaxial centre zone of the specimen are not high.

- For the wrought aluminium 2024-O, fatigue crack initiation occurred in the biaxial zone in the centre of the specimen for $100 \%$ of the specimens tested. The fatigue strength determined for the biaxial state, in terms of the first principle stress, is approximately 33\% higher than the corresponding value determined uniaxially. Hence, the presence of a second principal stress is beneficial in terms of fatigue.

- For the cast aluminium AlSi7Cu0.5Mg0.3, it was found that the zone of material at the centre of the specimen in which the biaxial stress state remains uniform is too small to ensure crack

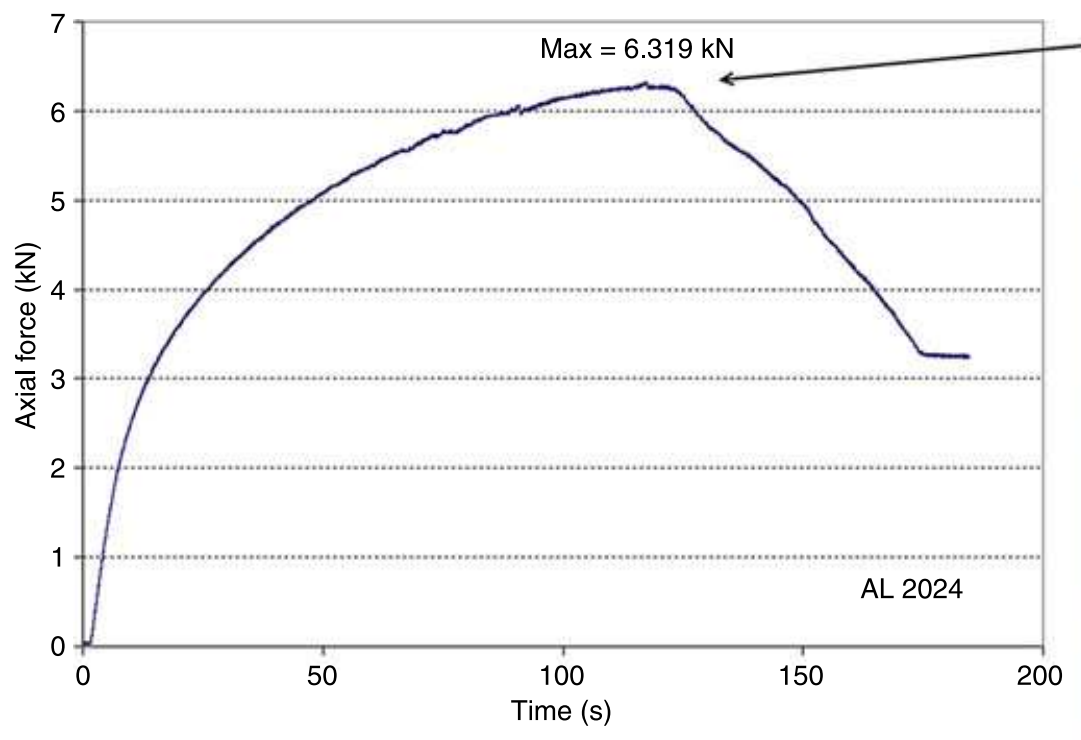

Drop in load when rupture occurs in the biaxial zone in the centre of the specimen

Figure 28: Monotonic tensile tests results using the biaxial specimen (Al 2024) 
initiation in this zone. This is because this material contains casting defects (micro-shrinkage pores) that are the order of $200 \mu \mathrm{m}$, which act as crack initiation sites. The likelihood of crack initiation in the biaxial zone therefore depends on the probability of finding a defect in this small volume. It is however expected that the specimen will be suitable for most non-cast metallic materials.

- It has been demonstrated that the biaxial specimen is also suitable for biaxial tensile tests, to determine the rupture strength of a material in a biaxial stress state.

It should also be noted that this type of specimen lends itself to the study of small-crack growth in a biaxial stress field. This is a topic of vital importance in many fields (e.g. military aircraft), as most of the fatigue life is confined to crack lengths under $1 \mathrm{~mm}$ growing under biaxial loadings.

The principal disadvantage of this type of specimen is that a finite element model is needed to determine the stress state. It has however been demonstrated, via a thermographic stress analysis and strain gauge measurements (outside the biaxial zone) that the finite element results give acceptably accurate results.

A limitation of the specimen is that since only one force is use to generate the biaxial stress field, it is not possible to generate a phase difference between the stress components. That is, only proportional loading conditions can be tested.

The biaxial specimen for uniaxial loading [15], described in this article, forms the object of the French patent FR 2914420.

\section{ACKNOWLEDGEMENTS}

The authors gratefully acknowledge the financial support of PSA - Peugeot Citroën and also that of the Conseil Général du Département de Maine-et-Loire, France.

\section{REFERENCES}

1. Issler, L. (1973) Festigkeitsverhalten Metallischer Werkstoffe bei Mehrachsiger Phasenverschobener Schwingbeanspruchung, PhD thesis, Universitat Stuttgart, Germany.

2. Mielke, S. (1980) Festigkeitsverhalten Metallischer Werkstoffe Unter Zweiachsig Schwingender Beanspruchung Mit Verschi- edenen Spannungszeitverlaufen, PhD thesis, RWTH Aachen, Germany.

3. Heidenreich, R., Richter, I. and Zenner, H. (1984) Schubspannungsintensitätshypothese - Weitere Experimentelle und Theoretische Untersuchungen, Konstruktion 36 H. 3, S. 99-104.

4. Simbürger, A. (1975) Festigkeitsverhalten Zäher Werkstoffe bei Einer Mehrachsigen, Phasenverschobenen Schwingbeanspruchung mit Körperfesten und Veränderlichen Hauptspannungsrichtungen, LBF Bericht Nr. FB-121 Darmstadt, Germany.

5. Mathiak, F., Krawietz, A., Nowack, H. and Trautmann, K.-H. (1992) Cruciform Planar Specimen for Biaxial Materials Testing, U.S. Patent 5144 844, issued Sep. 8, 1992.

6. Sawert, W. (1943) Verhalten der Baustähle bei Wechselnder Mehrachsiger Beanspruchung, Zeitschrift des Vereins Deutscher Ingenieure, VDI - Zeischrift Bd. 87, Nr 39/40, 2 Okt 1943.

7. Lebedev, A. A. and Mouzuika, N. R. (1980) Ukrainian Patent SU 769399 A1, issued 7 October 1980.

8. Clay, S. B. (1999) Biaxial Testing Apparatus, U.S. Patent 5905 205, issued May 18, 1999.

9. Dang Van, K. (1973) Sur la Résistance à la Fatigue des Métaux, Sciences et Techniques de l'armement, mémorial de l'artillerie française, 3eme facicule.

10. Dang Van, K., Griveau, B. and Message, O. (1989) On a new multiaxial fatigue criterion theory and application, Biaxial and Multiaxial Fatigue. In: EGF 3 (M.W. Brown and K.J. Miller, Eds). Mechanical Engineering Publications, London, 479-496.

11. Dang Van, K. (1993) Macro-Micro Approach in High-Cycle Multiaxial Fatigue, Advances in Multiaxial Fatigue. In: ASTM STP 1191, (D. L. McDowell and R. Ellis, Eds). American Society for Testing and Materials, Philadelphia, 1993, pp. 120-130.

12. Mura, T. (1987) Micromechanics of Defects in Solids, 2nd edn. Kluwer Academic Publishers, Dordrecht.

13. Papadopoulos, I. V. (1998) Critical plane approaches in high-cycle fatigue: on the definition of the amplitude and mean value of the shear stress acting on the critical plane. Fat. Fract. Eng. Mat. Struct. 21, 269-285.

14. Couper, M. J., Neeson, A. E. and Griffiths, J. R. (1990) Castings defects and the fatigue life of an aluminium casting alloy. Fat. Fract. Eng. Mat. Struct. 13, 213-227.

15. Morel, F., Bellett, D. and Morel, A., (2007) Eprouvette et procède d'essai de fatigue biaxiale d'un matériau métallique, French Patent FR 2914420 - A1, Issued 27 March 2007. 